\section{Refractive Error Profile in a Tertiary Centre in Western Nepal}

\section{Tuladhar S, ${ }^{*}$ Dhakal $S^{2}$}

\author{
${ }^{1}$ Department of Ophthalmology, Gandaki Medical \\ College, Pokhara, Nepal \\ ${ }^{2}$ Department of Medicine, Western Regional \\ Hospital, Pokhara, Nepal
}

\begin{abstract}
INTRODUCTION: Refractive error is one of the causes of avoidable blindness. Myopia, hypermetropia and astigmatism are the common types of refractive error. Not many studies are done to detect pattern of refractive error in Western Nepal. So, the study will determine the prevalence and distribution of refractive errors.
\end{abstract}

MATERIALS AND METHODS: A prospective study of all consecutive patients of age less than 40 years who visited eye department, Gandaki Medical College, between May 2010 and May 2011 was conducted. Visual acuity, naked eye and pin hole examination was done by ophthalmic assistant with cycloplegic refraction when needed. Those who did not turn up for refraction were excluded from the study.

RESULTS: A total of 601 patients were seen within the study period. Mean age of male patients was 22.4 years \pm 0.6 ( $95 \% \mathrm{CI}, 21.2-23.6$ years) and mean age of female patients was 24.2 years \pm 0.5 (95\% CI, 23.2-25.2 years). Majority of the patients were in age group 11-20 years (39.3\%). Myopia was the most common refractive error (43.3\%) followed by simple myopic astigmatism $(23.8 \%)$. Refractive errors were more common in females.

CONCLUSIONS: Myopia was the commonest refractive compared to hypermetropia. Refractive error was more common in females than in males. Such studies help to know the picture of refractive errors in community and such reports are helpful in planning programme to prevent avoidable blindness.

KEY WORDS: Myopia, Hypermetropia, Astigmatism

Article submitted 10 April. Reviewed 12 May. Author correction 20 May. Final version accepted 28 May 2013 


\section{INTRODUCTION}

To obtain clear vision, the eye must accurately focus an image in space on the retina. Refractive error is an anomaly of the dioptric system of the eye in which it fails to bring rays of light into a focus on retina. Myopia, hypermetropia and astigmatism are different types of refractive errors. Axial length of the eye, corneal curvature, position and refractive index of crystalline lens determine the refractive state of the eye.

There is compelling evidence for both genetic and environmental influence on refractive development.1,2,3 The specific genetic polymorphisms or environmental risk factors responsible remain largely unknown. Though earlier studies showed near work particularly reading, to be a significant environmental factor that may lead to myopia. $4,5,6 \mathrm{~A}$ susceptibility locus of myopia in the normal population is linked to the PAX6 region on chromosome 11.7

Uncorrected refractive errors are a common cause of visual impairment and blindness worldwide. It is estimated that 2.3 billion people are living with this disorder. ${ }^{8}$ Although most errors can be corrected by optical or surgical methods; these treatments have some drawbacks and pose a large economic burden.

Realizing the enormous need for correction of refractive errors worldwide, the World Health Organization has adopted the correction of refractive errors in developed and developing countries as one of the main priorities in its "Vision 2020: the right to sight" initiative. ${ }^{9}$ The pattern of refractive errors varies according to population characteristics such as age, gender and ethnic group.

The Nepal Blindness Survey done in 1981 showed that refractive error was a primary ocular disease in $1.3 \%$ of 39,887 patients in all age group. ${ }^{10}$ In 1998 , a population-based study conducted in school-age children in Eastern Nepal showed that $2.9 \%$ of children had visual morbidity of which $56 \%$ was due to refractive error. ${ }^{11}$ A similar study conducted in three schools of Kathmandu valley in 2002 found refractive error as the commonest (8.1\%) type of ocular morbidity. ${ }^{12}$

The study was done to note the pattern of refractive error in hospital setup. It is expected that this study will help in further research work and help to plan further services in refraction unit. As refractive errors are major causes of mild to moderate visual impairment in the population, knowledge of the prevalence of refractive errors would be helpful in planning public health strategies.

\section{MATERIALS AND METHODS}

A prospective study of all consecutive new patients of age less than 40 years who visited eye department, Gandaki Medical College, between May 2010 and May 2011 was conducted. An ophthalmic assistant took visual acuity of all patients first with naked eye then with pinhole and with glass for those wearing glass. Snellen's chart was used for literate and E chart for illiterate. Retinoscopy, objective and subjective refraction was done and auto refractor was used if needed. Cycloplegic refraction was done when needed.

The following definitions were used to classify the refractive error.

a) Hypermetropia: refractive error $\geq+0.50 \mathrm{D}$. This was further classified as low hypermetropia $(>+0.50 \mathrm{D}$ to $<+3.0 \mathrm{D})$, medium hypermetropia $(>+$ $3.0 \mathrm{D}$ to $<+6.0 \mathrm{D})$ and high hypermetropia $(>+6.0 \mathrm{D})$.

b) Myopia: Refractive error of $\geq-0.50 \mathrm{D}$. This was further classified as low myopia $(>-0.50 \mathrm{D}$ to $<-3.0 \mathrm{D}$ ), medium myopia (>-3.0D to <-6.0D) and high myopia (>-6.0D).

c) Astigmatism: any cylindrical error. Astigmatism was further classified as simple myopic astigmatism, simple hyperopic astigmatism, compound astigmatism and mixed astigmatism.

Astigmatism was further dived as "with the rule" when myopic astigmatism at $180 \pm 20^{\circ}$ or hypermetropic astigmatism at $90 \pm 20^{\circ}$, and "against the rule" when myopic astigmatism at $90 \pm 20^{\circ}$ or hypermetropic astigmatism at $180 \pm 20^{\circ}$. Astigmatism at $>20^{\circ}$ to $<70^{\circ}$ or $>110^{\circ}$ to $<160^{\circ}$ was considered as oblique astigmatism.

Patients having other diseases in the eye responsible for diminished vision like any retinopathy, squint, significant cataract, aphakia, pseudophakia and uncontrolled diabetes mellitus were excluded from the study. Patients with refractive error in only one eye or different refractive errors in both eyes were excluded from the study. Data was entered and analyzed using the Statistical Package for Social Science (SPSS v. 11.6)

\section{RESULTS}

During our study 601 patients had refractive errors. Among them 241 (40.1\%) were male, 360 (59.9\%) were female. 
Majority of patients were in age group 11-20 years (39.3\%). Details of age and sex distribution of patients are shown in table 1 .

Table 1. Age and sex distribution of patients

\begin{tabular}{lccc}
\hline $\begin{array}{l}\text { Age } \\
\text { group } \\
\text { (years) }\end{array}$ & \multicolumn{2}{c}{ Sex } & Total \\
\cline { 2 - 3 }$<10$ & $22(3.7 \%)$ & $16(2.7 \%)$ & $38(6.3 \%)$ \\
$11-20$ & $95(15.8 \%)$ & $141(23.5 \%)$ & $236(39.3 \%)$ \\
$21-30$ & $70(11.6 \%)$ & $100(16.6 \%)$ & $170(28.3 \%)$ \\
$>30$ & $54(9 \%)$ & $103(17.1 \%)$ & $157(26.1 \%)$ \\
\hline Total & $241(40.1 \%)$ & $360(59.9 \%)$ & $601(100 \%)$ \\
\hline
\end{tabular}

The mean age of male patients was 22.44 years \pm 0.62 SD (95\% CI 21.21-23.66 years) and that of female patients 24.28 years \pm 0.5 SD $(95 \%$ CI $=23.28-25.27$ years). In our study, 206 (34.3\%) were Brahmin, followed by Chhetri 133 (22.1\%), Gurung 87 (14.5\%), Newar 66 (11\%), Magar 41 $(6.8 \%)$ while $68(11.3 \%)$ were of other castes.

In our study, myopia was the most common type of refractive error compared to hypermetropia. Among myopia, $43.3 \%$ had simple myopia(SM), $23.8 \%$ had simple myopic astigmatism (SMA), and 13\% had compound myopic astigmatism (CMA). Among hypermetropia, $\quad 14 \%$ had simple hypermetropia(SH), $\quad 2.2 \% \quad$ had simple hypermetropic astigmatism(SHA), $1.7 \%$ had compound hypermetropic(CHA) astigmatis. Mixed astigmatism (MA) was seen in $2.2 \%$ of patients. Maximum refractive error (39.3\%) was seen in 1120 year age group followed by $28.3 \%$ in $21-30$ year age group, $26.1 \%$ in age group $31-40,6.3 \%$ in age group 0-10 year. Details are given in table 2 .
In our study, refractive errors were more common in females than on males. Table 3 shows gender wise distribution of refractive errors.

In our study, $47.9 \%$ of the patients had mild refractive error, $8 \%$ had medium refractive errors, and $1.8 \%$ had high refractive errors. With the rule astigmatism was seen in $5.3 \%$ patients, against the rule astigmatism was seen in $19.1 \%$ and oblique astigmatism in $0.8 \%$ patients. Details are shown in table 4.

\section{DISCUSSION}

Our study unlike other population based study showed predominance of females than males. This may be due to close proximity of this hospital to neighbourhood which has a greater female population. Similar result was seen in a study done in NMC ${ }^{13}$. However studies in

Table 3. Gender wise distribution of refractive errors

\begin{tabular}{lcc}
\hline Type of refractive error & Males & Females \\
\cline { 2 - 3 } & $\mathrm{n}(\%)$ & $\mathrm{n}(\%)$ \\
\hline Simple Myopia (SM) & $101(41.9)$ & $159(44.2)$ \\
$\begin{array}{l}\text { Simple Myopic } \\
\text { Astigmatism (SMA) }\end{array}$ & $54(22.4)$ & $89(24.7)$ \\
$\begin{array}{l}\text { Compound Myopic } \\
\text { Astigmatism (CMA) }\end{array}$ & $48(20)$ & $30(8.4)$ \\
$\begin{array}{l}\text { Simple Hypermetropia } \\
\text { (SH) }\end{array}$ & $26(10.8)$ & $58(16.1)$ \\
$\begin{array}{l}\text { Simple Hypermetropic } \\
\text { Astigmatism (SHA) }\end{array}$ & $5(2)$ & $8(2.2)$ \\
$\begin{array}{l}\text { Compound } \\
\text { Hypermetropic } \\
\text { Astigmatism (CHA) }\end{array}$ & $3(1.2)$ & $7(1.9)$ \\
$\begin{array}{l}\text { Mixed Astigmatism } \\
\text { (MA) }\end{array}$ & $4(1.7)$ & $9(2.5)$ \\
Total & $241(100)$ & $360(100)$ \\
\hline
\end{tabular}

Table 2. Patterns of refractive errors in different age groups

\begin{tabular}{lcccccccc}
\hline $\begin{array}{l}\text { Age } \\
\text { group } \\
\text { (years) }\end{array}$ & $\mathrm{SM}$ & $\mathrm{SMA}$ & $\mathrm{CMA}$ & $\mathrm{SH}$ & $\mathrm{SHA}$ & $\mathrm{CHA}$ & $\mathrm{MA}$ & \multirow{2}{*}{ Total } \\
\cline { 2 - 6 }$\leq 10$ & $12(2)$ & $\mathrm{n}(\%)$ & $\mathrm{n}(\%)$ & $\mathrm{n}(\%)$ & $\mathrm{n}(\%)$ & $\mathrm{n}(\%)$ & $\mathrm{n}(\%)$ & \\
\hline $11-20$ & $122(20.3)$ & $47(7.8)$ & $32(5.3)$ & $26(4.3)$ & $4(0.7)$ & $3(0.5)$ & $2(0.3)$ & $236(39.3)$ \\
& & & & & & & & \\
$21-30$ & $86(14.3)$ & $44(7.3)$ & $21(3.5)$ & $14(2.3)$ & $3(0.5)$ & $0(0)$ & $2(0.3)$ & \multirow{2}{*}{$170(28.3)$} \\
$\geq 30$ & $40(6.7)$ & $45(7.5)$ & $25(4.2)$ & $34(5.7)$ & $4(0.7)$ & $3(0.5)$ & $6(1)$ & $157(26.1)$ \\
\hline Total & $260(43.3)$ & $143(23.8)$ & $78(13)$ & $84(14)$ & $13(2.2)$ & $10(1.7)$ & $13(2.2)$ & $601(100)$ \\
\hline
\end{tabular}

SM, Simple Myopia; SMA, Simple Myopic Astigmatism; CMS, Compound Myopic Astigmatism; SH, Simple Hypermetropia; SHA, Simple Hypermetropic Astigmatism; CHA, Compound Hypermetropic Astigmatism; MA, Mixed Astigmatism 
Table 4. Grading of refractive errors

\begin{tabular}{lcccccccc}
\hline \multirow{2}{*}{$\begin{array}{l}\text { Age group } \\
\text { (years) }\end{array}$} & Mild & Medium & High & $\begin{array}{c}\text { With the } \\
\text { rule } \\
\text { astigmatism }\end{array}$ & $\begin{array}{c}\text { Against the } \\
\text { rule } \\
\text { astigmatism }\end{array}$ & $\begin{array}{c}\text { Oblique } \\
\text { astigmatism }\end{array}$ & Others & Total \\
\hline$\leq 10$ & $18(3)$ & $1(0.2)$ & $3(0.5)$ & $3(0.5)$ & $4(0.7)$ & $2(0.3)$ & $7(1.2)$ & $38(6.3)$ \\
$11-20$ & $114(19)$ & $31(5.2)$ & $4(0.7)$ & $10(1.7)$ & $38(6.3)$ & $0(0)$ & $39(6.5)$ & $236(39.3)$ \\
$21-30$ & $85(14.1)$ & $13(2.2)$ & $3(0.5)$ & $8(1.3)$ & $36(6)$ & $2(0.3)$ & $23(3.8)$ & $170(28.3)$ \\
$>30$ & $71(11.8)$ & $3(0.5)$ & $1(0.2)$ & $11(1.8)$ & $37(6.2)$ & $1(0.2)$ & $33(5.5)$ & $157(26.1)$ \\
Total & $288(47.9)$ & $48(8)$ & $11(1.8)$ & $32(5.3)$ & $115(19.1)$ & $5(0.8)$ & $102(17)$ & $601(100)$ \\
\hline
\end{tabular}

western countries showed female preponderance.

Uncorrected refractive errors are a major cause of visual impairment in many countries. ${ }^{9}$ In developing countries however; it is often difficult to provide efficient refraction services for a variety of reasons, and this result in a high prevalence of uncorrected refractive errors in these regions. The reported prevalence of refractive error varies in different areas of the world. Prevalence of refractive error ranges from $2.2-18.8 \%$ among the different studies.

Studies conducted in Kathmandu showed the prevalence of refractive error as 8.1\%; myopia: 4.3\%, hypermetropia: $1.3 \%, 12$ whereas a study in Mechi found the refractive error to be $2.2 \% .^{11}$ Different countries have various prevalence of refractive error, like $15.1 \%$ in India; ${ }^{14} 13.6 \%$ in Chile; ${ }^{15}$ 18.8\% in China. ${ }^{16}$

In our study myopia was the most common refractive error accounting for $43.3 \%$ of refractive errors and the most common age group for simple myopia was 21 to 30 years. Hypermetropia was found in $14 \%$ of population and it was common after 30 years of age. Females are more prone to have refractive errors than male.

In our study, myopia and myopic astigmatism was the most common refractive error followed by hypermetropia and hypermetropic astigmatism. This can be explained by the fact that majority of the patients were in young age group and were students and many of them sought ophthalmologist's advice for difficulty to see the blackboard in the classroom.

Similar findings were reported from a study in Pokhara which showed myopia was the commonest (36.1\%) type of refractive error followed by hypermetropia (31.6\%).17 Similar results showing myopia as the most common refractive error (68.2\%) followed by hypermetropia (27.4\%) was 6666seen in a study done in seen in a study done in Nepal medical college. ${ }^{13}$ Similar preponderance of myopia over hypermetropia was seen in a study done on school children in Nepal. ${ }^{15}$ Similar findings were reported in a study in South India. ${ }^{16}$

A study done in Lumbini Eye Institute, showed reported an entirely different scenario with astigmatism (47\%) as the commonest type of refractive error followed by myopia (34\%) and hyperopia (15\%) among children. ${ }^{20}$ Like wise a hospital-based study done in Kathmandu valley reported astigmatism (43.8\%) as the commonest error followed by hypermetropia (42.6\%) and then myopia (13.6\%). ${ }^{21}$

In our study most common age group of myopia was 11-20 years and that of hypermetropia was after 30 years of age. Similar findings showing myopia as the most commonly in $1^{\text {st }}$ to $3^{\text {rd }}$ decade and hypermetropia at 46-55 years of age was seen a study in NMC. ${ }^{13}$ A study in Pokhara also showed myopia mostly in age group 15-24 and hypermetropia in age group in age group 55-65. ${ }^{17}$

In our study, both myopia and hypermetropia were more common among females. But in other studies showed myopia more common in males and hypermetropia in females. ${ }^{22,23}$ from Singapore found in their study that after controlling for age, women had shorter axial lengths, shallower anterior chamber depths and shorter vitreous chamber depths than men, which may be the reason for the above finding.

In our study, different ethnic groups with refractive errors were Brahmins (34.3\%), Chhetris (22.1\%), and Gurungs (14.5\%). Similar findings showing most common ethnic groups as Brahmins, Gurungs, Newars were seen in a study in Pokhara. ${ }^{17}$ Similar predominance of Brahmins and newars over other ethnic groups were seen in a study by KJD in Kathmandu. ${ }^{21}$ 
In our study majority of patients had mild to moderate refractive errors. High refractive error was seen in $1.8 \%$ of patients. Similar findings (definition of high myopia was either >-5 D or >-6 D) were seen in a Baltimore eye survey (1.4\%), Shihpai Eye Study (2.3\%), a 13-Year Series of Population-Based Prevalence Surveys from Israel $(1.21 \%$ for males and 1.26 for females). The significance of high myopia is that it has a higher risk of cataract, glaucoma, myopic macular degeneration and retinal detachment, and the results of refractive surgery are less predictable in subjects with high myopia.

Myopic astigmatism was more common than hypermetropic astigmatism. Similar findings were seen in Nigeria and Zaire. ${ }^{24}$ "Against the rule astigmatism" was more common than "with the rule astigmatism". Similar findings were seen in other

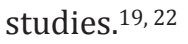

\section{CONCLUSION}

Myopia is the commonest refractive compared to hypermetropia. Refractive error is more common in females than in males. Such studies help to know the picture of refractive errors in community and such reports are helpful in planning programme to prevent avoidable blindness and achieve target of vision 2020 .

CONFLICT OF INTEREST: None to declare.

FINANCIAL INTEREST: None to declare.

\section{REFERENCES}

1. Stambolian D, Ciner EB, Raider LC, Moy C, Dana D, Owens R, et al. Genome-wide scan for myopia in the old order Amish. Am J Ophthalmol 2005:5469-5476.

2. Wojcie-Chowski R, Moy C, Ciner E, Ibay G, Reider L, Bailey-Wilson JE, et al. Genomewide Scan in Ashkenazi Jewish families demonstrates evidence of linkage of ocular refraction to a QTL on Chromosome Ip36. HumGenet 2006;119:389-399.

3. Hammond CJ, Sneider H, Gilbert CE, Spector TD. Genes and environment in refractive error: The Twin Eye Study. Invest Ophthalmol Vis Sci 2001;42:1232-1236.

4. Angle J, Wissmann DA. The epidemiology of Myopia. Am J Epidemiol 1980;11:220-228.

5. Saw SM, Katz J, Schein OD, Chew SJ and, Chan TK. Epidemiology of Myopia. Epidemiol Rev 1996;18:175187.

6. Goldschmidt E. The importance of heredity and environment in the aetiology of low Myopia. Acta Ophthamol 1981;59:759-762.

7. Hammond CJ, Andrew T, Mak YT Spector TD. A susceptibility locus for myopia in normal population is is linked to the PAX6 gene region on Chromosome 11: A genome scan of dizygotic twins. Am J Hum Genet 2004; 75:294-304.

8. Brien AH, Sylvie S, Kylie K. The challenge of providing spectacles in the developing world. Community Eye Health 2000;13:9-10

9. Dandona R, Dandona L. Refractive error blindness. Bull World Health Organization.2001;79:237-243.

10. Brilliant GB. The epidemiology of blindness in Nepal.Chelsea, Michigan. The Seva Foundation 1998.

11. Pokhrel GP, Negrel AD, Munoz SR, Ellwein LB. Refractive error study in children: results from Mechi Zone, Nepal. Am J Ophthalmol 2000; 29: 436-444.

12. Nepal BP, Koirala S, Adhikari S, Sharma AK. Ocular morbidity in school children in Kathmandu. Brit J Ophthalmic 2003;87:531-4.

13. Rizyal A, Ghising R, Shrestha RK, Kansakar I. Pattern of refractve errors among patients at a tertiary hospital in Kathmandu. Nepal Med Coll J 2011;13:172-174.

14. Murthy GV, Gupta SK, Ellwein LB, MuÃoz SR, Pokharel GP, et al. Refractive error in children in an urban population in New Delhi. Invest Ophthalmol Vis Sci 2002;43:623-31.

15. Maul E, Barroso S, Munoz SR, et al. Refractive error study in children: Results from La Florida, Chile. Am J Ophthalmol 2000;129:445-454.

16. Zhao J, Pan X, Sui R. et al Refractive Error Study in Children: results from Shunyi District, China. Am J Ophthalmol 2000. 129427-435.

17. Shrestha SP, Bhat KS, Binu VS, Barthakur R, Natarajan M, Subba S H. Pattern of refractive errors among the Nepalese population: a retrospective study. Nepal Ophthamol 2101;2:87-96.

18. Pokhreal A, Pokhreal PK, Das H, Adhikari S. The pattern of refractive errors among the school children of rural and urban settings of Nepal. Nepal J of Ophthalmol 2010;2;114-20.

19. Danoda R, Dandona L, Naduvillath T J, Srinivas M, Mc carty CA, Rao GN, Refractive errors in an urban population in South India: The Andra Pradesh Eye disease Study. Invest Ophthalmol Vis Sci 1999;40:2810-2818.

20. Rai (KC) S , Thapa H B, Sharma MK , Dhakhwa K , Karki R, The distribution of refractive errors among children attending Lumbini Eye Institute, Nepal. Nepal J Ophthalmol 2012;4:90-95

21. Karki KJD, Karki M. Refractive error profile- a clinical study. Kathmandu Univ Med J 2003;2:208-12.

22. Raju P, Ramesh SV, Arvind H, George R, Mani B, et al. Prevalence of Refractive Errors in a Rural South Indian Population. Investigative Ophthalmology \& Visual Science, December 2004;45:4268-4272.

23. Attebo K, Ivers RQ, Mitchell P. Refractive errors in an older population: the Blue Mountains Eye Study. Ophthalmol 1999;106:1066-1072.

24. Kaimbo-Wa-Kaimbo, Missotten. Ocular refraction in Zaire. Bull-Soc-Belge-Ophthalmol 1996;261:101-5.

\section{Citing this article}

Tuladhar S, Dhakal S. Refractive Error Profile in a Tertiary Centre in Western Nepal. Int J Infect Microbiol 2013;2(2):59-63. 